\title{
Effect of sex type, feeding regime and fat cover on eating quality of lamb
}

O R Oltra ${ }^{1,2}$, L J Farmer ${ }^{1}$, B Moss ${ }^{1}$, J Birnie ${ }^{3}$

${ }^{1}$ Queen's University Belfast, Belfast, United Kingdom, ${ }^{2}$ Agri-food and Biosciences Institute, Belfast, United Kingdom, ${ }^{3}$ Dunbia, Dungannon, United Kingdom

Email: ooltra01@qub.ac.uk

Introduction Research conducted in the last 20 years on lamb eating quality has shown that pre-slaughter factors such as lamb sex (Arsenos et al, 2002), diet (Priolo, 2001) and fat content and composition (Sanudo et al, 2000) can influence lamb acceptability to consumers. These factors and the interactions between them have highlighted the importance of the production system used to finish lambs on the eating quality of the meat, as perceived by consumers. This experiment was conducted with the aim of increasing the understanding of the role of sex, feeding regime and fat content and composition on the eating quality and nutritional attributes of lamb meat.

Material and methods Seven experimental groups (of 10 carcasses each) were selected according to their fat classification (EU classification), sex and feeding regime. All the lamb came from one farm in Wales where the sex types were finished separately. All the female lambs were finished with "new field (ryegrass) and rapeseed" (Nfr), the castrate lambs were finished either with "aftermath fields of cereal and concentrates" (Amc) or Nfr and the entire males were finished with Amc (Table 1).The carcasses were electrically stimulated with high voltage, fast chilled at $1^{\circ} \mathrm{C}$ for 4 hours and then stored at $2^{\circ} \mathrm{C}$ for 24 hours. The carcasses were boned and the $m$. longissimus dorsi and the leg were vacuum packed and aged for 7 days before being blast frozen. The $m$. $l$. dorsi, the $m$. adductor and vastus lateralis from the leg, were used for acceptability panels, while the $m$. $l$. dorsi and $v$. lateralis were used for fatty acid profiles and sensory profiling. In the hedonic panels 56 assessors scored the lamb on a scale of 1 (extremely acceptable) to 8 (extremely unacceptable). The sensory data (profiling and acceptability) and fatty acid profile were analysed by Random Effect Model.

Results Despite the differences in fat class, there were no differences in total intramuscular fat content $(\mathrm{P}>0.05)$ between the treatment groups. The fatty acid profiling gave statistically significant differences $(\mathrm{P}<0.05)$ in the content of some polyunsaturated fatty acids in both muscles. Entire males fed with concentrates had significantly higher contents of linoleic (C18:2), significant lower contents of linolenic acid (C18:3) and a significantly higher n-6/n-3 ratio compared with the rest of the groups. There were very few differences in sensory profiling results. In the acceptability panel of the m. Longissimus dorsi, statistically significant differences were found in the acceptability of flavour, texture in mouth, aftertaste and overall acceptability (Table 1). For all of these attributes, the meat from entire males was found to be less acceptable than the other experimental groups. There were no statistically significant differences $(\mathrm{P}<0.05)$ between the experimental groups in the consumer panels of the muscles adductor or $v$. lateralis, where the meat of all the groups were considered as "acceptable" for the panellist (score between 2.5 to 3.5 )

Table 1 Mean consumer acceptability (1 extremely acceptable to 8 extremely unacceptable) of grilled lamb steaks from the m. longissimus dorsi for the experimental groups studied

\begin{tabular}{|c|c|c|c|c|c|c|c|c|c|}
\hline \multirow{5}{*}{$\begin{array}{l}\text { Lamb sex } \\
\text { Fat Classification } \\
\text { Finishing system } \\
\text { Acceptability of }\end{array}$} & \multicolumn{7}{|c|}{ Experimental treatments } & \multirow[b]{5}{*}{ S.E.M. } & \multirow[b]{5}{*}{ Sig } \\
\hline & \multirow{4}{*}{$\begin{array}{l}\text { Male entire } \\
2-3 \mathrm{~L} \\
\text { Amc }\end{array}$} & \multicolumn{4}{|c|}{ Male castrate } & \multicolumn{2}{|c|}{ Female } & & \\
\hline & & $2-3 \mathrm{~L}$ & $3 \mathrm{H}-4 \mathrm{~L}$ & $2-3 \mathrm{~L}$ & $3 \mathrm{H}-4 \mathrm{~L}$ & $2-3 \mathrm{~L}$ & $3 \mathrm{H}-4 \mathrm{~L}$ & & \\
\hline & & Amc & Amc & Nfr & $\mathrm{Nfr}$ & $\mathrm{Nfr}$ & $\mathrm{Nfr}$ & & \\
\hline & & & & & & & & & \\
\hline Appearance & 2.5 & 2.6 & 2.7 & 2.7 & 2.6 & 2.6 & 2.6 & 0.132 & ns \\
\hline Aroma & 2.8 & 2.5 & 2.6 & 2.6 & 2.5 & 2.5 & 2.5 & 0.115 & $\mathrm{~ns}$ \\
\hline Flavour & $3.2^{\mathrm{c}}$ & $2.8^{\mathrm{b}}$ & $2.5^{\mathrm{ab}}$ & $2.7^{\mathrm{ab}}$ & $2.7^{\mathrm{ab}}$ & $2.8^{\mathrm{ab}}$ & $2.4^{\mathrm{a}}$ & 0.138 & $*$ \\
\hline Texture in the Mouth & $3.4^{\mathrm{c}}$ & $2.7^{\mathrm{ab}}$ & $2.6^{\mathrm{ab}}$ & $2.9^{\mathrm{b}}$ & $2.6^{\mathrm{ab}}$ & $2.9^{\mathrm{b}}$ & $2.4^{\mathrm{a}}$ & 0.150 & $* *$ \\
\hline After taste & $3.4^{\mathrm{c}}$ & $2.9^{\mathrm{ab}}$ & $2.9^{\mathrm{ab}}$ & $3.1^{\mathrm{bc}}$ & $3.1 b^{c}$ & $3.0^{\mathrm{b}}$ & $2.6^{\mathrm{a}}$ & 0.132 & $*$ \\
\hline Overall acceptability & $3.3^{\mathrm{c}}$ & $2.7^{\mathrm{ab}}$ & $2.6^{\mathrm{ab}}$ & $2.9^{\mathrm{ab}}$ & $2,8^{\mathrm{ab}}$ & $2.9^{\mathrm{b}}$ & $2.5^{\mathrm{a}}$ & 0.146 & $*$ \\
\hline
\end{tabular}

$* \mathrm{P}<0.05 ; * * \mathrm{P}<0.001$;S.E.M. $=$ standard error of means; ${ }^{\mathbf{a}, \mathbf{b}, \mathbf{c}}$ Values within a row that do not carry a common superscript are significantly different $(\mathrm{P}<0.05) ; \mathrm{ns}=\mathrm{P}>0.05$

Conclusions All muscles tested received good scores for acceptability, with no differences in fat content and few in fatty acids or sensory profiling attributes due to fat cover, sex or diet. Only the entire males gave slightly less acceptable loin and lower levels of n-3 fatty acids. Whether these were a result of gender or dietary differences would require further study.

\section{Acknowledgments}

The authors gratefully acknowledge funding from Dunbia

\section{References}

Arsenos, G., G. Banos, P. Fortomaris, N. Katsaounis, C. Stamataris, L. Tsaras, and D. Zygoyiannis. 2002. Meat Science 60, 379-387.

Priolo, A., D. Micol, and J. Agabriel. 2001. Animal Research 50, 185-200.

Sanudo, C., M. E. Enser, M. M. Campo, G. R. Nute, G. Maria, I. Sierra, and J. D. Wood. 2000. Meat Science 54, $339-346$. 